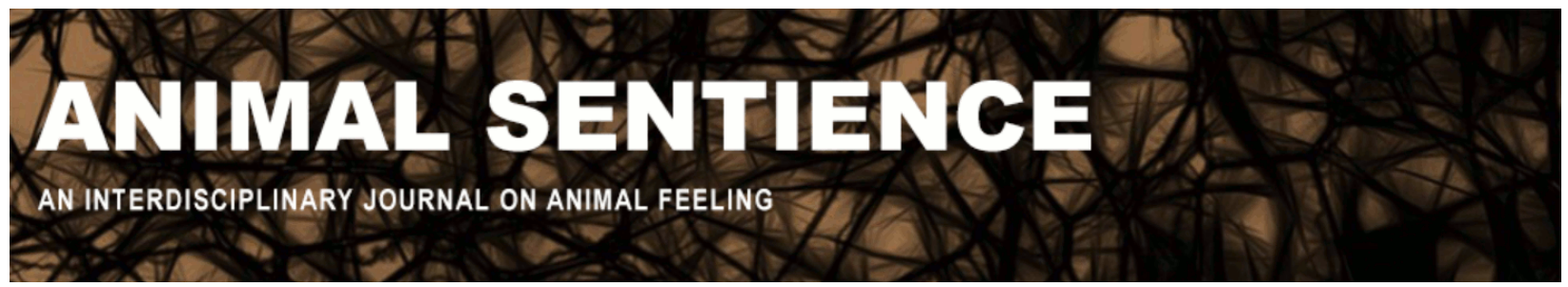

Celermajer, Danielle (2020) Rethinking rewilding through multispecies justice. Animal Sentience 28(12)

DOI: $10.51291 / 2377-7478.1570$

Date of submission: $2020-03-22$

Date of acceptance: 2020-04-01

(c)

This article has appeared in the journal Animal

Sentience, a peer-reviewed journal on animal

cognition and feeling. It has been made open access,

free for all, by WellBeing International and deposited

in the WBI Studies Repository. For more information,

please contact

wbisr-info@wellbeingintl.org.

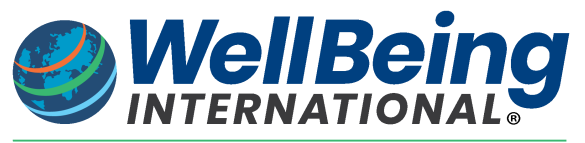

SOLUTIONS FOR PEOPLE, ANIMALS AND ENVIRONMENT 


\title{
Rethinking rewilding through multispecies justice
}

Commentary on Baker \& Winkler on Elephant Rewilding

\author{
Danielle Celermajer \\ Department of Sociology and Social Policy \\ University of Sydney
}

\begin{abstract}
Baker \& Winkler's argument that some humans, especially some Indigenous peoples, neither conceive of themselves as ontologically distinct from nature, nor do they organize their lives as such, is an important one. However, one needs to understand how colonialism and global capitalism have drawn Indigenous peoples and animals into new political economies. The new situation and the constrained opportunities available may have introduced a range of injustices or forms of violence that did not previously exist. This commentary proposes how a multispecies justice lens might assist in evaluating the most just arrangement for all parties, human and nonhuman.
\end{abstract}

Danielle Celermajer is Professor of Sociology and Social Policy at the University of Sydney and lead of the Multispecies Justice Project. Her work brings together human, animal and environmental justice in an effort to understand the ecology of injustice. Her publications include The Prevention of Torture: An Ecological Approach (Cambridge University Press, 2018). Website

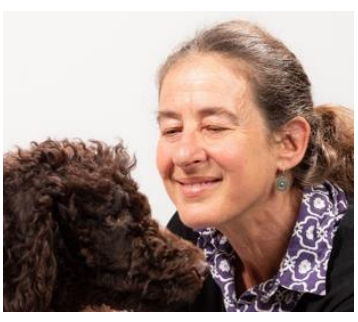

Baker \& Winkler's (2020) (B\&W) target article is framed in part as an argument that we ought to rethink current dominant conceptions of "wild". Specifically, they seek to contest the idea that when applied to nonhuman animals, "wild" necessarily entails rejecting all forms of human contact. In this way, B\&W might be seen as speaking to critiques (primarily in anthropology, but evident in some post-humanist literature more generally) of the dichotomy between nature and culture, and the idea that humans are essentially inimical to "nature" (MacCormack \& Strathern 1980, Haraway 2016). This argument is also continuous with Indigenous critiques of conservation as installing a notion of nature as necessarily free of people, thereby doing violence to the natureculture relationships within which they have existed (Tallbear 2015, de la Cadena 2018). In this regard, I note my disagreement with Kopnina's (2020) argument that there is no way of distinguishing who is Indigenous and who is not: Whereas there may be cases where there are counter-claims, there is a huge literature and a lot of politics on this, and Indigenous peoples have established working definitions that ought - in keeping with the right to self-determination set out in the United Nations Declaration on the Rights of Indigenous Peoples - to be respected (Dodson 1994, Pulitano 2012).

The argument that some humans, especially some Indigenous peoples, neither conceive of themselves as ontologically distinct from nature, nor do they organize their lives as such, is an important one. Nevertheless, when we come to examine the circumstances in which many Indigenous peoples now live, the "ideal" picture may well fail to capture contemporary realities. 
That is, even if there was once some type of balanced nature-culture in which humans and beings other than humans functioned according to a comprehensive set of norms (Stewart-Harawira 2012, Watene 2016), the mediation of colonization and imperialism may have so interfered with those relations that what is now available cannot be assessed as if the previous harmony still existed. The new situation and the constrained opportunities available may have introduced a range of injustices or forms of violence that did not previously exist. In the case discussed by $\mathrm{B} \& \mathrm{~W}$, for example, we are talking about a contemporary context where both Indigenous peoples and animals in Thailand have been subject to extensive intervention and domination and have, as a result of the establishment of hegemonic political and social systems, been drawn into alien economic and cultural systems. Both have had to accommodate themselves to survive these arrangements, and as a result, their relationships have been distorted. Hence even if one accepted that there was originally an ethically acceptable relationship between Indigenous peoples and animals (and Kopnina is right to critique the a priori view that any pre-colonial relationship between Indigenous peoples and animals must automatically be considered "ethical"), one needs to understand how both have been drawn into new political economies. The target article does a good job at tracing how the fates of elephants and mahouts alike have been subject to shifts in national and international political forces over which they had no say. In this sense, they have both been marginalised in the political economies within which they must now negotiate their lives.

One framework that might usefully be brought to the analysis is that of multispecies justice (Celermajer et al. 2020). Such a framework would insist that in assessing current options, we ask questions like: What are the diverse interests of all the human and non-human stakeholders?; How do existing power dynamics constrain the possibility of some interests being represented or realised?; Which forms of life and what types of provisions and arrangements will best allow for all concerned to exercise their capacities (Schlosberg 2007)?; How do we balance the demand to accommodate the existing situation (as Suter 2020 argues) against ethical claims of those whose interests have been systematically ignored?; Which existing arrangements do we consider beyond contestation or fixed (i.e., elephant tourism) and for what reasons?

In assessing the most just arrangement in the context of proposals for policy reform and intervention, feasibility needs to be a consideration, as I have argued elsewhere (Celermajer 2018). In this regard, Suter (2020) is right to insist that reform proposals regarding the situation of elephants in Thailand not ignore current realities. Nevertheless, Suter's argument might be criticized for naturalising the constrained options, rather than even entertaining what a just arrangement might look like - one that would take into account the interests of elephants, Karen and the forests, for example. This does not mean that reform to certain arrangements will not be strongly resisted, nor that such reform will be without costs to certain parties, including vulnerable ones. Nevertheless, the costs and who bears them, as well as the benefits, and to whom they accrue, need to be weighed and the correct balance not assumed. 


\section{References}

Baker, L., \& Winkler, R. (2020). Asian elephant rescue, rehabilitation, and rewilding. Animal Sentience 28(1).

Celermajer, D. (2018). The prevention of torture; An ecological approach. New York: Cambridge University Press.

Celermajer, D., Chatterjee, S., Cochrane, A., Fishel, S., Neimanis, A., O’Brien, A., Reid, S., Schlosberg, D., Srinivasan, K., \& Waldow, A. (2020, in press). Justice through a multispecies lens. Contemporary Political Theory.

De la Cadena, M. (2018). A world of many worlds. Durham: Duke.

Dodson, M. (1994). The Wentworth lecture the end in the beginning: Re(de)finding aboriginality. Australian Aboriginal Studies 1: 2-13.

Haraway, D. (2017). Staying with the trouble. Durham: Duke.

Harawira, M. (2012). Returning the sacred: Indigenous ontologies in perilous times. In L. Williams, R. Roberts, \& A. McIntosh (Eds.), Radical human ecology: Intercultural and Indigenous approaches (pp. 73-88). UK: Ashgate.

Kopnina, H. (2020). Of elephants and men. Animal Sentience 28(2).

MacCormack, C., \& Strathern, M. (Eds.). (1980). Nature, culture and gender. Cambridge University Press.

Pulitano, E. (Ed.). (2020). Indigenous rights in the age of the UN declaration. Cambridge University Press.

Schlosberg, D. (2007). Defining environmental justice: Theories, movements, and nature. Oxford: Oxford University Press.

Suter, I. (2020). Rewilding or reviewing: Conservation and the elephant-based tourism industry. Animal Sentience 28(3).

TallBear, K. (2015). An Indigenous reflection on working beyond the human/not human. GLQA Journal of Lesbian and Gay Studies 21(2-3): 230-235.

Watene, K. (2016). Valuing nature: Māori philosophy and the capability approach. Oxford Development Studies 44(3): 287-296. 


\section{Call for Papers}

Special Issue of the Journal of Consciousness Studies

Plant Sentience: Theoretical and Empirical Issues

Guest Editors: Vicente Raja (Rotman Institute of Philosophy, Western University) Miguel Segundo-Ortin (School of Liberal Arts, University of Wollongong)

In this special issue, we address the issue of plant sentience/consciousness from different disciplines that combine both theoretical and empirical perspectives. Some of the questions to be addressed in the special issue include the following:

- Plants exhibit interesting behaviors; does this entail that they are conscious to some extent?

- What are the requirements for a living organism to be conscious? Do plants meet these requirements?

- What does the possibility of plant sentience/consciousness entail for the study of the evolution of consciousness?

- Is it just a categorical mistake to attribute consciousness to plants?

- Can we talk about different levels or degrees of consciousness?

\section{How to submit?}

Deadline: June 1 1st $^{\text {, } 2020}$

Please submit your papers (max. 9000 words including footnotes, references, abstract, etc.) to vgalian@uwo.ca with subject "Paper Special Issue JCS".

For more information, including bibliography and more detailed descriptions of the topics and questions to be addressed in the papers submitted to the special issue, please contact the guest editors at vgalian@uwo.ca (Vicente) or ms0693@uowmail.edu.au (Miguel). 